\title{
Link between Crustal Magnetization and Earthquakes in Taiwan
}

\author{
Shu-Kun Hsu*, Yi-Ching Yeh, Chung-Liang Lo, Andrew Tien-Shun Lin, and Wen-Bin Doo \\ Institute of Geophysics, National Central University, Chung-Li, Taiwan, ROC
}

Received 2 May 2007, accepted 28 September 2007

\begin{abstract}
The active Taiwan orogen is located between the Ryukyu subduction zone in the northeast and the Manila subduction zone in the south. Intensive collision from the northwestward motion of the Luzon Arc has induced enormous earthquakes in and around Taiwan. In this paper, we attempt to relate the occurrence of earthquakes in Taiwan to crustal magnetization. For that, we have inverted magnetic anomalies to obtain an equivalent crustal magnetization distribution in the Taiwan region. In general, high magnetization zones are considered as relatively rigid zones. In contrast, weak zones can be compressed as a result of lateral plate convergence, causing intensively crustal deformation and earthquakes. The Lukang Magnetization High (LMH), located in mid-west Taiwan, is suggested to dominate earthquake occurrence in middle Taiwan. Historically large earthquakes in Taiwan are mostly distributed around the eastern side of the LMH. If we take into account the northwestward convergence of the Luzon Arc or the Philippine Sea Plate, the area to the southeastern side of the LMH actually incubates more earthquake hazards. The crust of relatively low magnetization in mid-central Taiwan has been compressed and escaped sideward; intensive compression has also caused thicker crust and the depths of crustal earthquakes in middle Taiwan may be as deep as $40 \mathrm{~km}$. Although both the eastern Central Range and the Luzon Arc show relatively high magnetizations, the Luzon Arc may be intrinsically less stable because of its younger and hotter nature; thus, the Luzon Arc has historically displayed severe internal deformation and produced numerous earthquakes as a result of plate collision.
\end{abstract}

Key words: Magnetization, Earthquake, Crust, Collision, Plate convergence

Citation: Hsu, S. K., Y. C. Yeh, C. L. Lo, A. T. Lin, and W. B. Doo, 2008: Link between crustal magnetization and earthquakes in Taiwan. Terr. Atmos. Ocean. Sci., 19, 445-450, doi: 10.3319/TAO.2008.19.5.445(T)

\section{INTRODUCTION}

Great earthquakes usually occur at convergent plate boundaries. Two types of convergent boundaries are generally involved. The first one is associated with a subduction process where a plate subducts beneath another plate along a trench and earthquakes occur at the plate interface or a seismogenic zone, like the earthquakes off west Chile and off eastern Japan. Another type is related to a collision zone where a mountain belt may be created, like the Pakistan-Tibet region. However, the mechanism for the occurrence of great earthquakes is still not very clear, though it is frequently explained geometrically by a seismic gap or a seismic asperity (Scholz 1990). Here we attempt to relate the occurrence of earthquakes, especially great earthquakes, to crustal magnetization. To this end, we examine earthquakes and crustal magnetization distributed in the Taiwan

\footnotetext{
* Corresponding author
}

E-mail:hsu@ncu.edu.tw mountain belt.

Taiwan is located between two subduction systems: the Philippine Sea Plate subducts northward beneath the Ryukyu Arc while the Eurasian Plate subducts eastward beneath the Luzon Arc (Ho 1988; Angelier 1990) (Fig. 1). In between, the Taiwan mountain belt has been created by the collision of the Luzon Arc against the southeast Eurasian margin in the direction of ca. $N 310^{\circ}$ (Seno 1977; Yu et al. 1997; Sibuet and Hsu 2004), inducing numerous earthquakes in this region. In mid-west Taiwan, the occurrence of earthquakes and crustal deformation have been frequently linked to a pre-Miocene basement high called the Peikang High (e.g., Hu et al. 2001; Lin et al. 2003) (Fig. 1). In this study, we will show that the existence of the Peikang High may not be so important. In contrast, we will demonstrate that one of the main factors dominating earthquake occurrence and crustal deformation in the Taiwan orogen is crustal magnetization. 


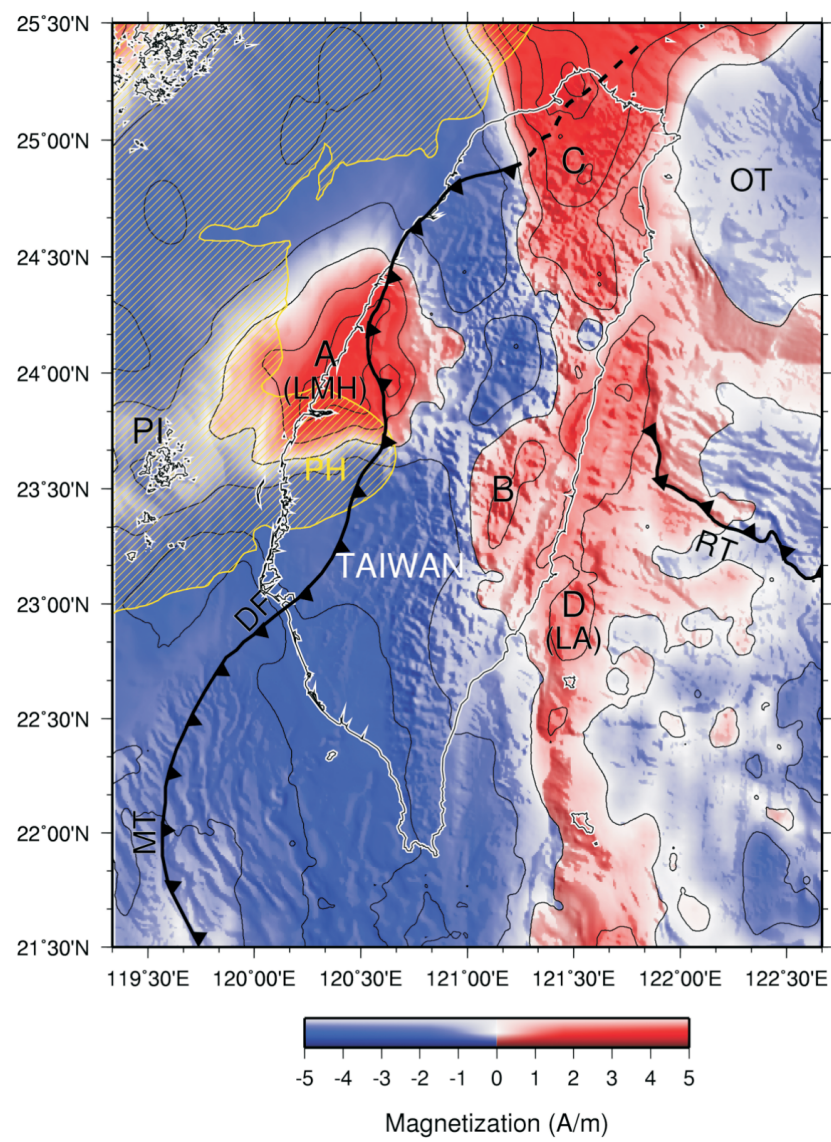

Fig. 1. Distribution of equivalent magnetization values in and around Taiwan. The yellow hachured zone indicates the Pre-Miocene basement at $4 \mathrm{~km}$ deep. DF: deformation front; LA: Luzon Arc; LMH: Lukang magnetization high; MT: Manila Trench; OT: Okinawa Trough backarc basin; PH: Peikang High (a geometric basement high); PI: Penghu islands; RT: Ryukyu Trench.

\section{EQUIVALENT CRUSTAL MAGNETIZATION}

To understand the magnetic characteristics of the Taiwan area, we have conducted a magnetization inversion by using the magnetic anomalies of Hsu et al. (1998) and Wang et al. (2002). The study region is divided into $6 \times 6 \mathrm{~km}$ grids and we assume that the magnetic anomalies originate from an equivalent layer of constant thickness of $6 \mathrm{~km}$. The magnetization direction is presumed to be the same as the present-day geomagnetic field. A slight change of the geomagnetic parameters, including the equivalent thickness of the magnetized layer, would not significantly change the similar pattern of magnetization distribution. The calculated crustal magnetization is shown in Fig. 1.

Our results show that relatively high magnetization values are distributed in four zones: zones A, B, C, and D in Fig. 1. A high magnetization generally reflects the nature of igneous rocks and is not necessarily associated with a basement high. Thus, we may consider that a high magnetization zone corresponds to a zone of relatively rigid crust. Zone A is located to the north of the Peikang High (Fig. 1). To dif- ferentiate it from the Peikang High, we name the high magnetization zone A as the Lukang Magnetization High (LMH). Lukang is a town near the center of zone A. As evidenced by several deep boreholes, the deep portion of the $\mathrm{LMH}$ is Paleogene and Miocene intermediate to mafic volcanic rocks that may attain a few hundreds of meters in cumulative thickness and are encased in sedimentary layers (Lin et al. 2003). These extrusive volcanic rocks and high magnetization in the LMH suggest the existence of deepseated intrusive rocks of intermediate to mafic origin in the crustal level. Zone B is located at the eastern Central Range (Fig. 1). Although there are no deep igneous rocks reported yet, some mafic igneous bodies are found at the surface of zone B (Ho 1988). Zone C generally follows the trend of the western edge of the subducted Philippine Sea Plate. Some andesitic volcanoes, such as the Tatun volcanoes, are distributed at the surface (Ho 1998). This high magnetization zone trending NWN-SES may be related to magmatic activity along the western edge of the Philippine Sea Plate (Lin et al. 2004). The elongated zone D generally reveals the presence of the N-S trending volcanic Luzon Arc.

\section{EARTHQUAKE DISTRIBUTION, CRUSTAL DEFORMATION, AND MAGNETIZATION}

Superposing the earthquake epicenters shallower than $50 \mathrm{~km}$ on the magnetization map of Fig. 1, we can find that most of the crustal earthquakes in Taiwan are distributed in zones of relatively low magnetization (cf. Figs. 2, 3), except for earthquakes associating with the Ryukyu and Manila subduction zones. In contrast, the areas of the $\mathrm{LMH}$ and zone B display dramatically fewer earthquakes (Figs. 2, 3). These two zones might be traditionally considered "seismic gaps" and might incubate future great earthquakes in an actively colliding zone. We consider that the $\mathrm{LMH}$ and zone B are inherently more rigid in crustal strength; accordingly, most brittle deformation and earthquakes may occur in the compressed areas between these two rigid zones. Actually, high magnetization zones, such as the LMH, may not be rigid enough to prevent all kinds of ruptures. This possibility can be ascribed to equivalent magnetization, which is simply an average effect, with, in fact, high magnetization zones being more or less heterogeneous. As igneous rocks are usually intrusive, the deeper part of the crust may exhibit larger strength. As shown in Fig. 1, the deformation front crosses the LMH and some shallow earthquakes have occurred inside the LMH. Because the deformation front delimits the surface and western boundary of compressive structures, its presence indicates that the uppermost part of the LMH is not so rigid. However, the uppermost crust cannot accumulate large elastic energy in terms of crustal strength. In other words, the crustal strength generally increases as a function of depth. Because of the increasing plate convergence, the compressed area bordering the LMH 
is vulnerable to rupture because compressive stress can more easily overcome the yield strength here than in the area of the LMH. This is evidenced by the surface rupture along the Chelungpu Fault (Ma et al. 1999; Kao and Chen 2000) which is located just to the east of the LMH (Fig. 2).

Zone B has a characteristic of low seismicity and high heat flow, while the LMH has low siesmicity and low heat flow (Lee and Cheng 1986; Lin 2000). This indicates that the low seismicity ("seismic gap") of zone B can not be mainly ascribed to high heat flow that weakens crustal strength. In contrast, the LMH and Zone B both display high magnetization areas, which suggest that low seismicity may be ascribed to higher crustal strength in terms of magnetization. On the other hand, although the Luzon Arc is of igneous origin and belongs to a high magnetization zone, it has produced numerous crustal earthquakes (Figs. 2, 3). This suggests that the collision of the Luzon Arc against eastern Taiwan (i.e., the Tananao metamorphosed complex) has made the Luzon Arc internally deformed in a brittle way. This phenomenon is probably because of the younger and hotter nature of the Luzon Arc; therefore, the Luzon Arc could be intrinsically less rigid than zone B in eastern Taiwan.

The most active Taiwan orogeny is found in the central portion (Lo and Hsu 2005) and it is not isostatic (Hsu and Lo 2004). As shown by the distribution of magnetizations, the low magnetization zone is narrowest in central Taiwan (Fig. 1). It is also noted that deep crustal earthquakes as deep as $40 \mathrm{~km}$, also cluster in central Taiwan east of the LMH (Figs. 2, 3). These phenomena reflect intensive crustal thickening and uplifting in mid-central Taiwan. Here, crustal deformation is in fact not only limited to vertical motion. As evidenced by earthquake focal mechanisms (Rau and Wu 1998; Kao and Chen 2000), the crust of the low magnetization zone in mid-central Taiwan has shown a tendency to escape sideways (Fig. 4). This crustal escape may also be ascribed to the weaker crust between the high magnetization zones. As evidenced by the existence of high magnetization zones and the distribution of earthquakes in Taiwan, this suggests that the whole crustal portion (Hsu and Sibuet 1995; Sibuet and Hsu 2004), or the lithospheric portion (Wu et al. 1997) could be involved in Taiwan orogeny.

\section{POTENTIAL GREAT EARTHQUAKES IN TAIWAN}

Historically, great earthquakes of magnitude greater than 6 are numerous in and around Taiwan (Fig. 5). Because of the high crustal strength, the colliding Luzon Arc may accumulate more strain energy before a great earthquake occurs. Besides which, the great earthquakes of Taiwan are surprisingly distributed around the eastern edge of the LMH (Fig. 5). Based on the relationship between earthquake magnitudes and seismic moments (Wang 1992), we can calculate the spatial distribution of the released seismic moments for earthquakes shallower than $50 \mathrm{~km}$ from 1898 to 2005 (Fig. 6). The minute-by-minute released seismic moments in each grid are summarized. The results show that the area surrounding the east side of the LMH displays a high concentration of released seismic moments (Fig. 6). It indicates that the existence of the LMH is strongly related to the occurrence of great earthquakes in Taiwan. If we take into account the northwestward convergence of the Philippine Sea Plate relative to the Eurasian Plate, it seems that great earthquakes in Taiwan mainly occur to the southeast of the LMH, in a trend roughly perpendicular to the direction of plate convergence. The 1999 Chi-Chi earthquake and its aftershocks of magnitude greater than 6 (Figs. 2, 5) also fit the above zone. However, the Chi-Chi earthquake sequence seems to have occurred at a seismic gap on the southeast side of the LMH (Fig. 5). In a collisional mountain belt zone, if we don't consider crustal magnetization distribution, we may regard a high magnetization zone such as LMH a zone of

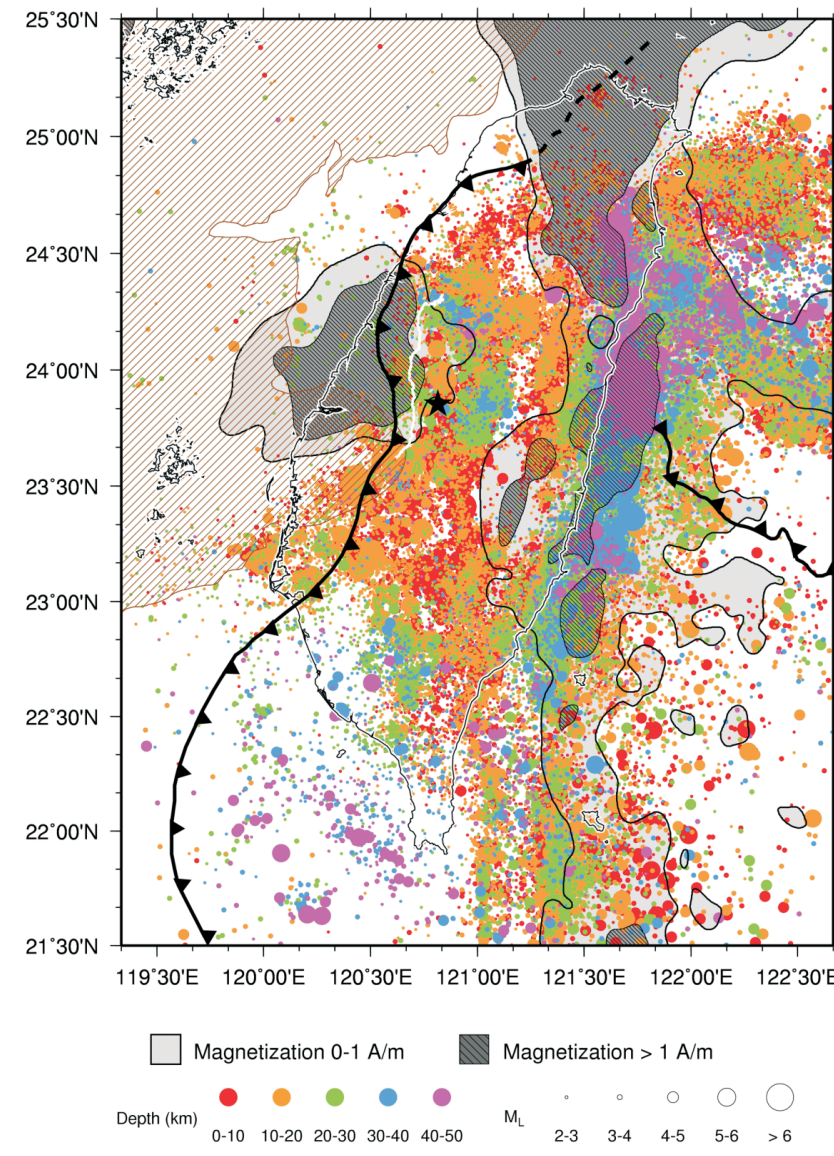

Fig. 2. Epicenters of earthquakes shallower than $50 \mathrm{~km}$ in the Taiwan region from 1991 to 2005. Except for the earthquakes in the rifting Okinawa Trough backarc basin and the earthquakes associated with the Ryukyu and Manila subduction zones, most of the crustal earthquakes in Taiwan are located in zones of low magnetization (cf. Fig. 1). The white line in western Taiwan indicates the surface trace of the Chelungpu Fault and the black star represents the epicenter of the 1999 Chi-Chi great earthquake. The rest of the symbols are the same as in Fig. 1. 


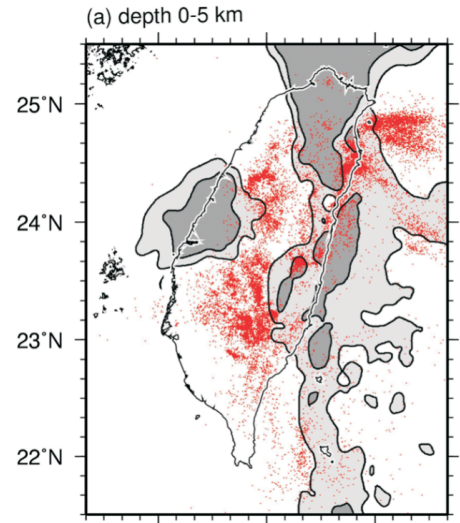

(e) depth $20-25 \mathrm{~km}$

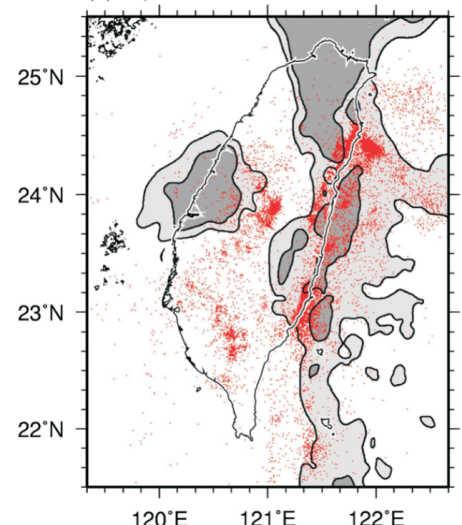

(b) depth $5-10 \mathrm{~km}$

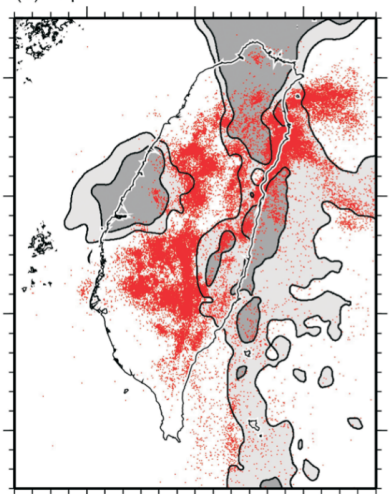

(f) depth $25-30 \mathrm{~km}$

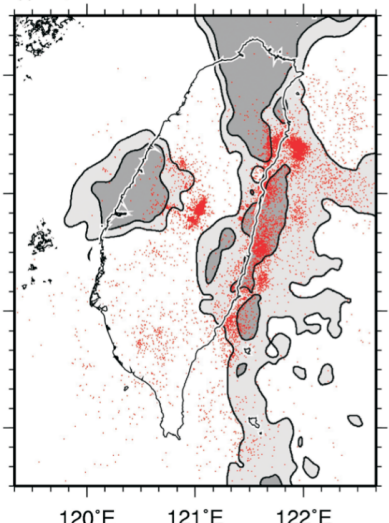

(c) depth $10-15 \mathrm{~km}$

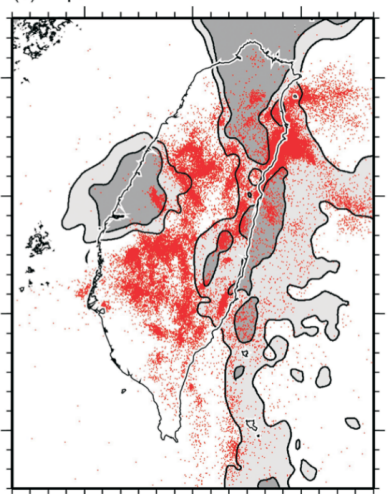

(g) depth $30-35 \mathrm{~km}$

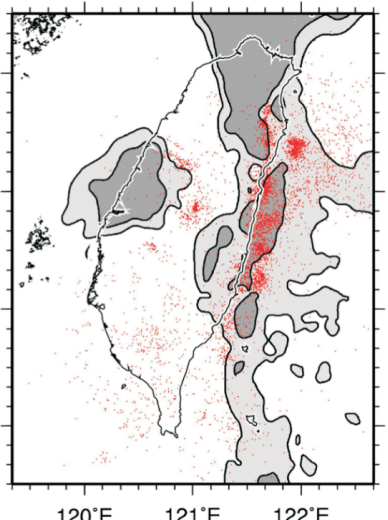

(d) depth $15-20 \mathrm{~km}$

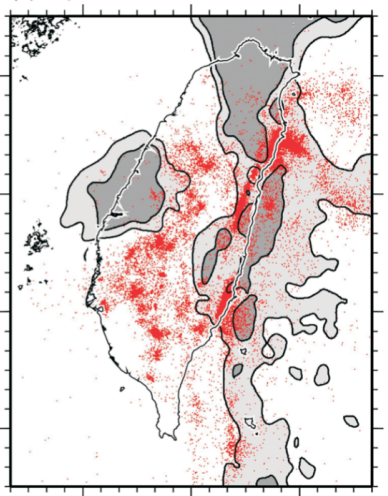

(h) depth $35-40 \mathrm{~km}$

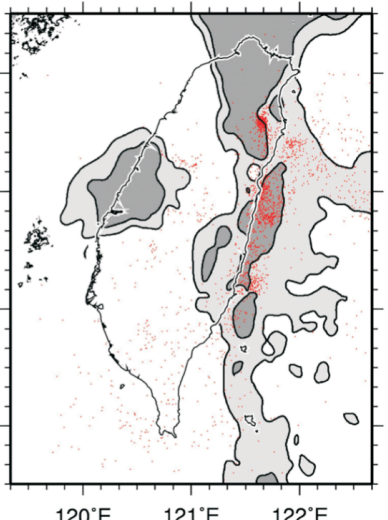

Fig. 3. Depth distribution of crustal earthquakes (same as in Fig. 2). ${ }^{\#}$ Note that inside Taiwan most of earthquakes have occurred in the low magnetization zones. The shaded zones indicate the high magnetization zones as shown in Fig. 1.

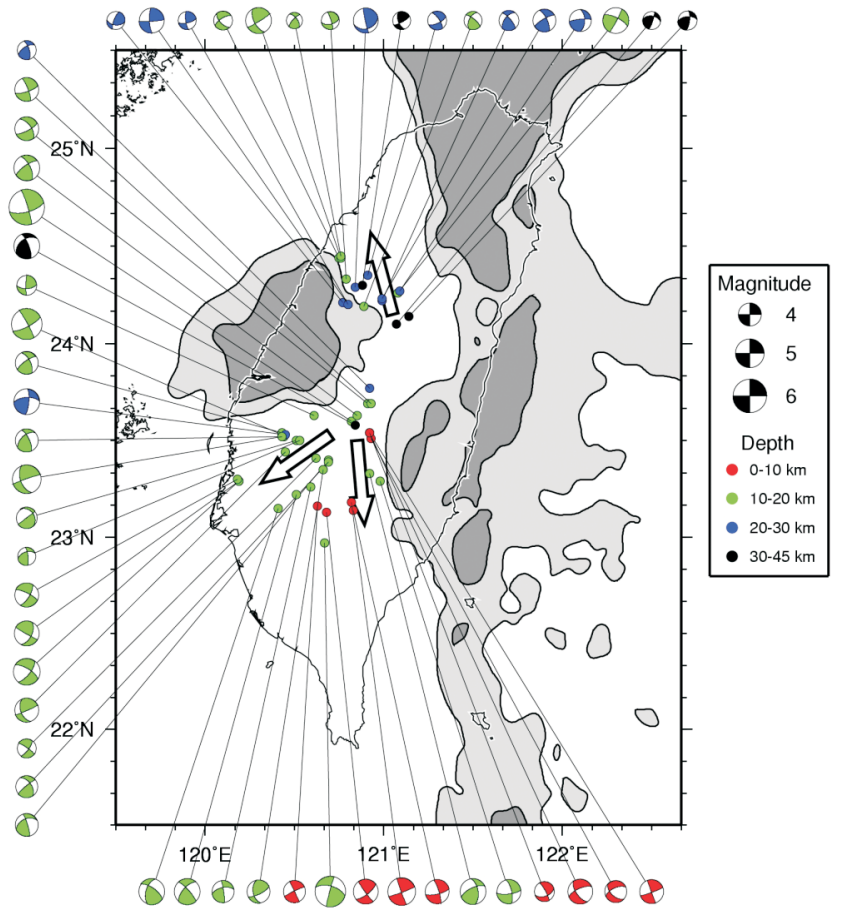

Fig. 4. Strike-slip earthquake focal mechanisms in central Taiwan (Rau and Wu 1998; Kao and Chen 2000). The strike-slip deformation in low magnetization zones of central Taiwan is interpreted as extrusive tectonics due to convergence of two adjacent high magnetization zones.
$M_{\mathrm{L}}$ ○6-7 $\bigcirc>7$ Blue (1898-1990) Red (1991-2005)

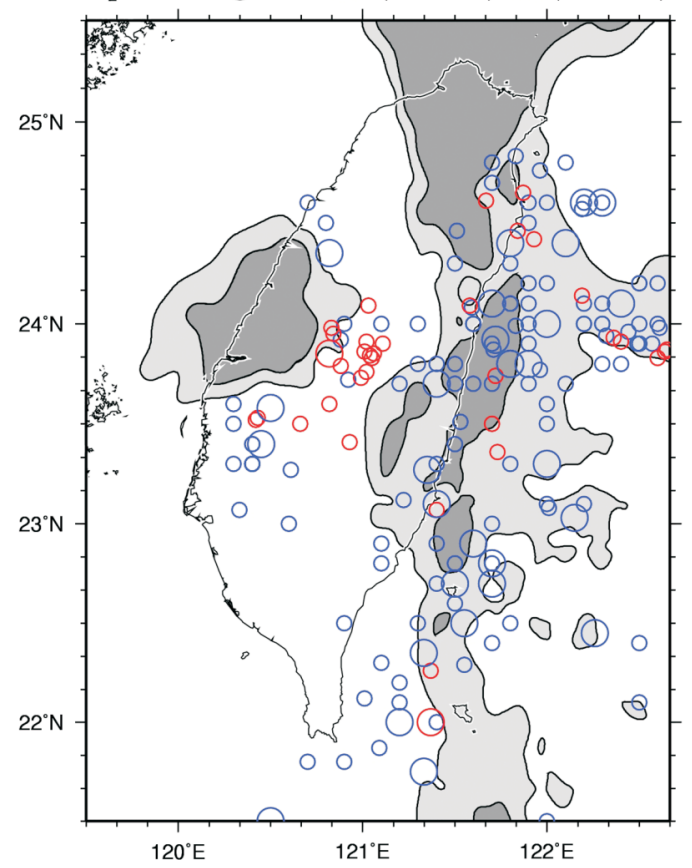

Fig. 5. Great earthquakes in Taiwan, reported after the installation of seismometers in Taiwan since 1898. The shaded zones indicate the high magnetization zones as shown in Fig. 1. Note that inside Taiwan most of great earthquakes are located in the low magnetization zones and around the LMH. 
1898-2005 Cumulative Crustal Seismic Moment

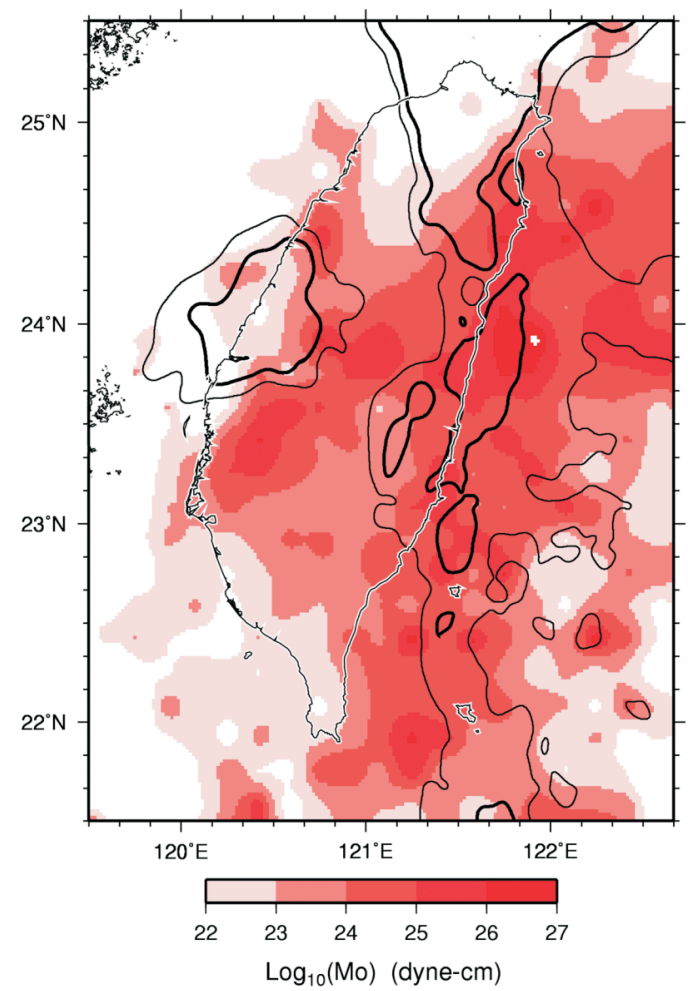

Fig. 6. Accumulation of the seismic moments released from earthquakes shallower than $50 \mathrm{~km}$ in the Taiwan region. The contour lines indicate the high magnetization values of 2 and $1 \mathrm{~A} \mathrm{~m}^{-1}$ shown in Fig. 1.

seismic gap. However, a seismic gap must be an area that is prone to generate great earthquakes but is seismically quiescent. That is, a high magnetization zone must be considered as a relatively rigid zone and earthquakes generally occur in the surrounding low magnetization zone. Examining seismicity in a similar magnetization context may help to identify really seismic gaps.

\section{CONCLUSION}

To better understand the earthquake behavior in the Taiwan region, we have compared crustal earthquake characteristics to the equivalent crustal magnetization inverted from magnetic anomalies in and around Taiwan. In the Taiwan region, four relatively high magnetization zones can be identified. The existence of a relatively high magnetization zone called the Lukang Magnetization High (LMH) in midwest Taiwan is suggested to dominate the earthquake occurrence in middle Taiwan. Historically great earthquakes of inland Taiwan are mostly distributed in the southeastern side of the LMH. Another high magnetization zone, zone B, is located in eastern Taiwan. The relatively low magnetization zone in between has been compressed and generates enormous earthquakes. The crust in middle Taiwan has thickened and tended to escape sideway. Compared to zone B or the eastern Central Range, the Luzon Arc is also a high magnetization zone but it is less strong. Continuous plate convergence has caused severe internal deformation and numerous earthquakes along the Luzon Arc. We may conclude that crustal magnetization can be used as a proxy of crustal strength. Thus, crustal magnetization distribution and the locations of seismic gaps are two important factors in signaling the potential great earthquakes in a collision zone, such as the Taiwan orogen.

Acknowledgements This study was conducted under a grant of National Science Council, Taiwan, ROC. We appreciate valuable comments from associated editor Prof. Ling-Yun Chiao and two anonymous reviewers.

\section{REFERENCES}

Angelier, J, 1990: Geodynamic evolution of the eastern Eurasian margin. Tectonophysics, 183, $362 \mathrm{pp}$.

Ho, C. S., 1988: An Introduction to the Geology of Taiwan: Explanatory Text of the Geologic Map of Taiwan. In: Ministry of Economic Affairs, $2^{\text {nd }}$ Edition, Taipei, Taiwan, $192 \mathrm{pp}$.

Hsu, S. K. and J. C. Sibuet, 1995: Is Taiwan the result of arccontinent or arc-arc collision? Earth Planet. Sci. Lett., 136, 315-324.

Hsu, S. K. and C. L. Lo, 2004: Change of crustal gravitational potential energy in the Taiwan orogen by the Chi-Chi earthquake sequence. Earth Planet. Sci. Lett., 222, 573-581.

Hsu, S. K., C. S. Liu, C. T. Shyu, S. Y. Liu, J. C. Sibuet, S. Lallemand, C. Wang, and D. Reed, 1998: New gravity and magnetic anomaly maps in the Taiwan-Luzon region and their preliminary interpretation. Terr. Atmos. Ocean. Sci., 9, 509-532.

Hu, J. C., S. B. Yu, J. Angelier, and H. T. Chu, 2001: Active deformation of Taiwan from GPS measurements and numerical simulations. J. Geophys. Res., 106, 2265-2280.

Kao, H. and W. P. Chen, 2000: The Chi-Chi earthquake sequence: Active out-of-sequence thrust faulting in Taiwan. Science, 288, 2346-2349.

Lee, C. R. and W. T. Cheng, 1986: Preliminary heat flow measurements in Taiwan, Presented at the Fourth CircumPacific Energy and Mineral Resources Conference, Singapore.

Lin, A. T., A. B. Watts, and S. P. Hesselbo, 2003: Cenozoic stratigraphy and subsidence history of the South China Sea margin in the Taiwan region. Basin Res., 15, 453-478.

Lin, C. H., 2000: Thermal modeling of continental subduction and exhumation constrained by heat flow and seismicity in Taiwan. Tectonophysics, 324, 189-201.

Lin, J. Y., S. K. Hsu, and J. C. Sibuet, 2004: Melting features along the western Ryukyu slab edge (northeast Taiwan): Tomographic evidence. J. Geophys. Res., 109, B12402, doi: 10.1029/2004JB003260. 
Lo, C. L. and S. K. Hsu, 2005: Earthquake-induced gravitational potential energy change in the active Taiwan orogenic belt. Geophys. J. Int., 162, 169-176.

Ma, K. F., C. T. Lee, and Y. B. Tsai, 1999: The Chi-Chi, Taiwan earthquake: Large surface displacements on an inland thrust fault. EOS Trans. AGU, 80, 605-611.

Rau, R. J. and F. T. Wu, 1998: Active tectonics of Taiwan orogeny from focal mechanisms of small-to-moderatesized earthquakes. Terr. Atmos. Ocean. Sci., 9, 755-778.

Scholz, C. H., 1990: The mechanics of earthquakes and faulting. Cambridge Univ. Press, Cambridge, UK.

Seno, T., 1977: The instantaneous rotation vector of the Philippine Sea Plate relative to the Eurasian Plate. Tectonophysics, 42, 209-226.

Sibuet, J. C. and S. K. Hsu, 2004: How was Taiwan created?
Tectonophysics, 379, 159-181.

Wang, C., C. P. Huang, L. Y. Ke, W. J. Chien, S. K. Hsu, C. T. Shyu, W. B. Cheng, C. S. Lee, and L. S. Teng, 2002: Formation of the Taiwan island as a solitary wave along the Eurasian continental plate margin: Magnetic and seismological evidence. Terr. Atmos. Ocean. Sci., 13, 339-354.

Wang, J. H., 1992: Magnitude scales and their relations for Taiwan earthquakes: A review. Terr. Atmos. Ocean. Sci., 3, 449-468.

Wu, F. T., R. J. Rau, and D. Salzberg, 1997: Taiwan orogeny: Thin skinned or lithospheric collision? Tectonophysics, 274, 191-220.

Yu, S. B., H. Y. Chen, and L. C. Kuo, 1997: Velocity field of GPS stations in the Taiwan area. Tectonphysics, 274, 41-59. 